\title{
Evaluation of Possum Scoring in Patients Undergoing Emergency Laparotomy for Hollow Viscus Perforation
}

\author{
Dr.R.Manivannan ${ }^{1}$, Dr.M.Prabhakaran ${ }^{2}$ \\ ${ }^{l}$ professor of surgery, MADRAS medical college \\ ${ }^{2}$ Resident in surgery,Madras medical college,
}

\begin{abstract}
Back Ground And Objectives: POSSUM and P-POSSUM equations have been validated and used extensively in general surgery and subspecialties, but its use in emergency setting has not been that extensively studied.

Hence the aim of the present study was to evaluate the efficacy of POSSUM scoring as a risk assessment tool in predicting morbidity and mortality for patients undergoing Emergency laparotomy for hollow viscus perforation and to study the correlation between accepted and institutional standards.

Results: This prospective, observational, descriptive study was conducted among 100 purposively selected patients who had underwent emergency midline laparotomy for hollow viscus perforation in the emergency department of Institute of General Surgery, Madras Medical College, Chennai .The study was carried out in a view to determine the validity of POSSUM scoring in predicting the morbidity and mortality in patients undergoing emergency midline laparotomy. The standards of our institution compared to the general accepted level of morbidity and mortality was also analysed. In our study there were a total of 100 patients studied. All the patients underwent midline laparotomy incision with appropriate procedures as per their pathology. 37 percent of the patients developed morbidity. The most common being wound dehiscence, followed by wound infection, UTI, Pneumonia, ARDS and anastomotic leak. Four patients among the study group died due to MODS.Among the four patients died, the POSSUM predicted mortality percentage was more than ninty percent in three of the patients. This indicates high level of sensitivity in predicting the mortality.

But in the case of morbidity the expected and observed ratios differed. Chi square analysis of significance of POSSUM score to predict morbidity and mortality among the study group showed a high level of significance for mortality of $<0.005$ but in case of morbidity it is about 0.3 .

Conclusion: From our study, it has been evaluated that POSSUM scoring in patients with perforation peritonitis is a significant tool to evaluate the mortality and morbidity outcomes of the patients.
\end{abstract}

\section{Introduction}

Crude morbidity and mortality rates are limited indicators of quality of care, and can be misleading when the results of emergency surgery are compared between different units and hospitals. Scoring systems that group patients based on the severity of illness before treatment can allow a meaningful analysis of morbidity and mortality rates. Risk-adjusted comparisons can then be made between surgeons and hospitals. The Physiological Operative Severity Score for the enumeration of Mortality and morbidity \{POSSUM $\}$ is widely used to predict morbidity and mortality in widely used to predict morbidity and mortality in a variety of surgical settings, and provides a tool for risk adjustment and comparison. In contrast Acute Physiological And Chronic Health Evaluation II, it takes the operative findings into consideration. All 12 physiological and 6 operative variables required for POSSUM scoring can be recorded easily and reproduced satisfactorily by resident staff with minimal difficulty. Any comparative system that over predicts mortality and morbidity has theeffect of making poor results look better. The Portsmouth predictor modification $\{$ P-POSSUM $\}$ proposed by Whiteley et al. counters the over prediction of mortality in low risk patients by POSSUM. The variables used are the same but a differentformula is used to predict the risk of death. Differences in predictive values of two scoring systems are related to the method of analysis. Wijesinghe et al. directly compared the exponentialand linear methods of analysis; use of linear analysis for POSSUM or exponential analysis for P-POSSUM yielded spurious results by over predicting mortality. The case mix of patients undergoing emergency laparotomy is varied, especially in developing countries. Those seeking medical help are of low socioeconomic status, are nutritionally depleted and at times present very late in the course of their illness. Comparing the outcome for such patients using data from developed countries or centres with selection bias may be misleading.

\section{Physiological And Operative Severity Score For Enumeration Of Mortality And Morbidity}

The Physiological and Operative Severity Score for enUmeration of Mortality and morbidity $\{$ POSSUM $\}$ has been devised specifically for prediction in surgical patients. It uses 12 physiological and six operative variables to give a calculated risk of morbidity and death. POSSUM was intended to be used in 
comparative surgical audit. Calculated risks of death can be compared with the actual outcomes to give a observed to expected ration. This is an effective tool for surgical patients in general and also in specific groups, such as patients with vascular and colorectal disease, although it has been found to give an overestimation of expected mortality rate among the patients at lowest risk. In a comparison with the APACHE II score assessing outcome prediction for surgical patients in a high-dependency unit, the POSSUM score was of greater value. As operative factors form an integral part of the scoring system it isuseful only in patients who undergo an operation. This excludes approximately one third of surgical patientsPortsmouth modification of Physiological and Operative Severity Score for enUmeration of Mortality and morbidity Whiteley et al. have proposed the Portsmouth modification of POSSUM \{PPOSSUM\} to counter their finding that POSSUM overpredicts the mortality rate. The same variables were used but a different formula was used to calculate the mortality risk. When the expected mortality rate for the group was derived from a linear analysis of all the individual mortality risks, this modification gave a more accurate prediction. However if an exponential analysis was employed the original POSSUM was more accurate.

The POSSUM mortality equation as published by Copeland et al is in $\{\mathrm{R} /(1-\mathrm{R})\}=-7.04+(0.13 \mathrm{x}$ physiological score $)+(0.16 \mathrm{x}$ operative score $)$, where $\mathrm{R}$ is the predicted risk of mortality and is in the standard form of equation as produced by logistical regression. An initial trial of POSSUM involving 1485 patients was performed and used published methods for the application and analysis of logistical regression models. The POSSUM mortality equation was found to over predict mortality by a factor greater than 2 . This over prediction was greatest by six fold\} amongst low-risk patients \{those with risk of mortality of $10 \%$ or less \}, who form majority of general surgical patients in a district general hospital setting. The approach was then modified using standard methods to obtain a logistic regression model that fitted well with the observed mortality.

The POSSUM data set was developed over 2years by Copeland et al. Initially 62 individual factors \{48 preoperative factors and 14 operative and postoperative factors $\}$ were assessed by a multivariate discriminant retrospective analysis over a six month period to reduce the number of variables. Of these 35 factors were assessed prospectively for a further six months to present scoring system. In this later prospective analysis all variables were subjected to multivariate discriminative analysis and, using the linear discriminant technique, multivariate discriminant function coefficients were obtained for each set of variables. Only significant factors were included in the final score design. The multivariate discriminant function coefficients of those remaining factors were divided by a constant and rounded to the nearest whole number to derive an point value on an exponential score $\{1,2,4,8\}$ for the variable. Thus a 12 -factor, four grade, physiological score was developed. Any decrease in score variables below this level resulted in a loss of predictive ability for mortality or morbidity. While this preoperative physiological score yields a statistically predictive risk of morbidity and mortality for the patients overall, there are intergroup differences depending on the nature of surgical procedure. Logistic regression analysis of all data enabled a six-factor, surgical, operative severity score to be evolved which compensated for the type of surgical procedure. Operative scores ranged from 1 to 8 , depending on the size and severity of the operation. Finally the combined preoperative physiology and operative scores were subjected to logistic regression analysis to generate a risk equation that changed the scores into a predicted percentage mortality and morbidity. The system was tested prospectively for six months to confirm the accuracy in predicting outcome after general surgical operations.

\section{Regression Equations And Methods Of Analysis}

There is much confusion about the way POSSUM scores are analyzed. The result of the POSSUM data set is physiology score of 12-88 and operative score of 6- 44. Although the higher the overall POSSUM score, the greater the risk of morbidity and mortality, individual scores do not reflect the percentage risk. These two scores are most useful as a part of a regression equation that is used to produce a percentage risk. The regression equation includes a constant number and weighted scores for physiology and operative risk $\{(\mathrm{R} / 1-\mathrm{R})=-7.04+$ $(0.13 \mathrm{xPS})+(0.16 \mathrm{xOS})\}$. A different constant and weighted value is needed to predict morbidity and mortality. This original system was used for the first 5 years, but many variations have since been published. The initial equation used a new technique called exponential analysis; this works out the number of deaths in a particular group in the following way. The number of people in, for example, the band with a predicted risk of 50-60\% is calculated by working out the number with a risk greater than $50 \%$ and subtracting the number with a risk more than $60 \%$. This is not a standard statistical technique and has attracted criticism owing to the difficulty of giving a risk score to an individual. The number in a given range is also dependent on how many people are in other groups. Odd results occur occasionally, such as a negative predicted risk

(negative number of deaths in a risk group). In this case the risk band is widened till it contains a positive number of deaths. Despite these criticisms, POSSUM scoring using the original equation and exponential analysis did predict outcome in general surgery. However later authors particularly from Portsmouth, UK, could not reproduce the predictive power of the equation and criticized the analytical technique, although not he POSSUM data set. 
Evaluation of Possum Scoring In Patients Undergoing Emergency Laparotomy for Hollow Viscus..

\section{Pitfalls In Data Collection And Analysis}

Mistakes have been made in both data collection and analysis using POSSUM.Some authors have been criticized for recording their data in such a way as to alter the predicted mortality. Most of the POSSUM physiology and operative data seem Straight forward, but methods must be standard to be valid. First, the POSSUM physiology score may change with time. For example, and elderly patient admitted with septicemia from a diverticular abscess, who is aggressively resuscitated before the operation, should have an improving physiological score. The authors of the original research used data taken as close to the time of operation as possible- the last recorded values before the patient entered the anesthetic room. It could be argued that surgeons could improve their results artificially by selecting and recording the patient's worst physiology score. This does not matter if all the surgeons agree to score at the same stage. There is room for further research into whether improving the physiology score by resuscitation improves overall outcome after operation. Mellroy et al. reported that preoperative resuscitation could improve physiology scores and that outcomes were poor in patients who failed to respond to resuscitation. Missing data remain a problem. In many cases, the results of some physiological data are not available. For some patients, tests such as chest radiography are not justified clinically. It is misconception that such radiography is a required variable; raised JVP and shortness of breath at rest already give the highest cardiorespiratory score, and confirmation be imaging is not required. Investigations are performed on patients when there is reasonable suspicion that they are abnormal. In the absence of a test result, the variable is currently scored one \{i.e. presumed to be normal\}. There are also problems with specific data variables. The electrocardiogram $\{\mathrm{ECG}\}$ seems to cause the most confusion. A normal ECG scores 1, including normal variants such as right bundle branch block or sinus dysrhythmia. The middle category \{score 2 \} includes slow atrial fibrillation or old myocardial damage. Recent myocardial damage or evidence of myocardial ischemia score 8 , the highest value. However, the highest score category also includes miscellaneous items. Confusion can occur easily if minor, non specific ECG changes are scored in this miscellaneous category.The operative score has an element of subjective assessment. The exact volume of blood loss may not be easy to determine, although the amount is cored in relatively broad bands. Peritoneal soiling has been inadvertently misscored in the past; some surgeons believe that all patients having elective repair of aortic aneurysm have maximum peritoneal contamination, but peritoneal soiling should be scored on opening the abdomen and excludes blood. All of these problems could be eased by creation of comprehensive explanatory sheet for surgeons using POSSUM scoring.

\section{Value Of Possum In General Surgery}

The idea behind POSSUM was to enable a fair comparison between individual surgeons and individual hospitals. Most of the original possum validation wascarried out on general surgical procedures. The first paper modeled a general surgical population; it excluded both pediatric surgeries, because physiological parameters in children differ from those of adults, and day-case surgery, where there is low incidence of morbidity and death. POSSUM has since been used to compare the performance of individual surgeons. In a study of 3006 general surgical episodes by five surgeons from a single hospital, crude mortality rates were compared with risk adjusted outcomes \{calculated from POSSUM observed: expected ratios\}.

In this paper POSSUM out performed the intensive care scoring system, acute physiology and chronic health evaluation \{APACHE II, in predicting mortality. POSSUM has also been used to assess the safety of transferring critically ill patients between the intensive care units of different hospitals. A criticism of POSSUM is that it applies only to surgical patients, and only to those who have an operation. Several authors have used the physiology component of the POSSUM score for patients who did not have a surgical procedure. In one study, 35110 surgical admissions were analyzed; the authors created a new regression equation that predicted mortality in the group, irrespective of whether an operation was performed or not. The authors suggested this could become a national minimum data set for all surgical admissions. It has the advantage of including patients too sick to undergo a surgical procedure. The physiology component of the POSSUM score has been evaluated in some non-surgical procedures. In a study of patients who had intra-arterial thrombolysis for acute leg ischemia, the POSSUM physiology score predicted mortality effectively. Indeed, it is possible to predict mortality in surgical procedures, too, using only the physiology score; some of the best prediction equations in vascular surgical procedures were obtained without employing the operative data IV-POSSUM and VPOSSUM physiology only\}.

\begin{tabular}{l} 
POSSUM \\
This was the initial mortality equation. It is the only equation to require exponential analysis $(\mathrm{R} / 1-\mathrm{R})=-7.04+(0.13 \times \mathrm{PS})+(0.16 \times$ \\
OS $)$ \\
\hline P-POSSUM \\
This was the modification of the first equation; it requires linear analysis, as do all the following equations. P-POSSUM is \\
applicable to general surgical patients. \\
$(\mathrm{R} / 1-\mathrm{R})=-9.065+(0.1692 \times \mathrm{PS})+(0.1550 \times \mathrm{OS})$ \\
\hline RAAA-POSSUM
\end{tabular}




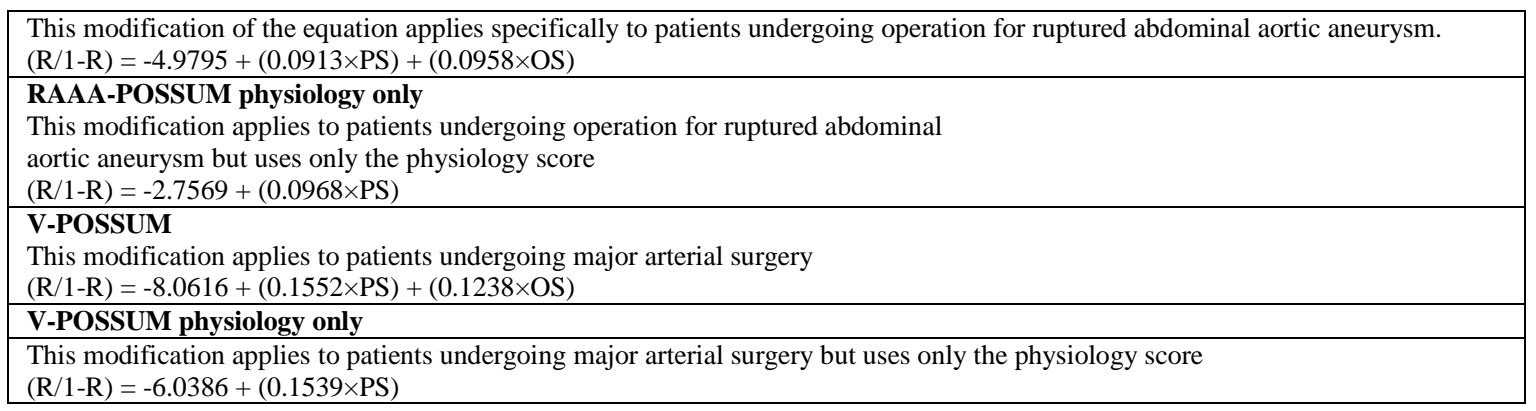

\title{
III. Patients And Methods
}

Some 100 patients who underwent emergency laparotomy from January 2015 to sepetember 2015 at madras medical college and Hospital were studied. Data were collected prospectively on a pro forma prepared for the study. All patients had their physiological score recorded on admission. An operative severity score was calculated based on the findings of the operative surgeon on the pro forma. Any post operative morbidity and death within 30 days were recorded based on the following definitions:

\author{
Morbidity : definitions \\ Wound haemorrhage : local haematoma requiring evacuation. \\ Deep haemorrhage: postoperative bleeding requiring re-exploration.
}

Chest infection: production of purulent sputum with positive bacteriological cultures, with or without chest radiography changes or pyrexia, or consolidation seen on chest radiograph.

Wound infection: wound cellulitis or the discharge of purulent exudates.

Urinary infection: the presence of $>105$ bacteria / $\mathrm{ml}$ with the presence of white cells in the urine, in previously clear urine.

Deep infection: the presence of an intra-abdominal collection confirmed clinically or radiologically.

Septicemia: positive blood culture.

Pyrexia of unknown origin: any temperature above $37^{\circ} \mathrm{C}$ for more than $24 \mathrm{~h}$ occurring after the original pyrexia following surgery (if present) had settled, for which no obvious cause could be found.

Wound dehiscence: superficial or deep wound breakdown.

Deep venous thrombosis and pulmonary embolus: when suspected, confirmed radiologically by venography or ventilation/ perfusion scanning or diagnosed at post mortem.

Cardiac failure: symptoms or signs of left ventricular or congestive cardiac failure (alteration from preoperative measures)

Impaired renal function: arbitrarily defined as an increase in blood urea of $>5 \mathrm{mmol} / 1$ from preoperative levels.

Hypotension: a fall in systolic blood pressure below $90 \mathrm{mmHg}$ for more than $2 \mathrm{hr}$ as determined by sphygmomanometry or arterial pressure transducer measurement

Respiratory failure: respiratory difficulty requiring emergency ventilation.

Anastamotic leak: discharge of bowel content via the drain, wound or abnormal orifice. The data were entered into Microsoft Excel \{Microsoft Corporation, Redmond, Washington, USA \} for analysis. The risk of morbidity and death was calculated using POSSUM and P-POSSUM equations, which are as follows:

POSSUM Equation:

Risk of morbidity $=\left(0.16^{*}\right.$ physiologic score $)+(0.19 *$ operative score $)-5.91$

Risk of mortality $=0.13 *$ physiologic score $)+(0.16 *$ operative score $)-7.04$

P-POSSUM Equation:

Risk of mortality $=(0.1692 *$ physiologic score $)+(0.1550 *$ operative score $)-9.065$

POSSUM and P-POSSUM scores are a part of regression analysis but use different and constant values for physiological and operative scores to predict mortality and morbidity. Data were analyzed using both exponential and linear methods of analysis described by Wijesinghe et al. The ratio of observed to expected deaths $\{\mathrm{O}: \mathrm{E}$ ratio $\}$ was calculated for each analysis. A chi-square test was used to detect any differences between predicted and observed rates of morbidity and mortality. P $<0.050$ was accepted as significant.

\section{Inclusion Criteria}

1. Age above 12 y. Patients less than $12 \mathrm{y}$ of age are managed by the Department of Paediatric Surgery in our hospital.

2. Patients with established peritonitis following hollow viscus perforation.

3. Patients with intra-peritoneal abscess due to hollow viscus perforation. 


\section{Exclusion Criteria}

1. Age 12 y and below.

2. Patients undergoing emergency explorative laparotomy due to other causes like abdominal trauma.

3. Patients with primary peritonitis due to tuberculosis alcoholic cirrhosis, nephrotic syndrome, cardiac failure or systemic lupus erythematosus.

\section{Discussion}

This prospective,observational,descriptive stud y was conducted among 100 purposively selected patients who had underwent emergency midline laparotomy for hollow viscus perforation in the emergency department of institute of general surgery,madras medical college, Chennai.the study was carried out in aview to determine the validity of POSSUM scoring in predicting the morbidity and mortality in patients undergoing emergency midline laparotomy.the standards of our institution compared to the general accepted level of morbidity and mortality was also analysed.

In our study there were a total of 100 patients studied.among them 87 were males and 13 were females .the age of patients studied were from 15 to 80 .most of the patients were in age group of $40 \mathrm{t} 0$ 50.all the patients underwent midline laparotomy incision with varying procedures like appendectomy, resection anastomosis, omental patch closure and primary closure closure of the perforation. two patient had malignant etiology one with gastric growth and the other with colon growth.37 percent of the patients developed morbidity .the most common being wound dehiscence, followed by wound infection, UTI, pneumonia, ARDS, and anastamotic leak. four patients among the study group died due to MODS

With regards to mortality, the low rates in the study precludes meaningful analysis. among the four patients died ,the POSSUM predicted mortality percentage was more than ninty percent in three of the patients. this indicates high level of sensitivity in predicting the mortality. But in the case of morbidity the expected and observed ratios differed. Chi-square analysis of significance of POSSUM score to predict morbidity and mortality among the study group showed a high level of significance for mortality of $<0.005$ but in case of morbidity it is about 0.3 .

\section{Conclusion}

Morbidity and mortality rates continue to be the main endpoints by which quality of care is judged in most institutions in developing countries such as India. Patients undergoing emergency laparotomy have diverse etiologies and associated co- morbid conditions the can influence the outcome adversely. Patients seeking medical help in government institutions like this one mostly belong to low socioeconomic strata with very limited resources. Under such circumstances, measuring the quality of care using morbidity and mortality may be biased.

The POSSUM data set provides a good tool for monitoring the quality of care provided by a particular institution by making adequate risk adjustments. The validity of POSSUM scoring systems has been verified over the past decade and a half for use in general surgery and different subspecialties, including vascular, colorectal, gastroenterological, pulmonary and orthopedic surgery. With practice it is possible to calculate the score in $90 \mathrm{~s}$, and free packages are available on the internet to assist. The predictive power of the two equations is related to the statistical method used for analysis. POSSUM scoring as developed by Copeland et al. used the exponential method of analysis. This has been criticized for not being a standard statistical technique, and is difficult to give a risk score to an individual patient by this method. P-POSSUM on the other hand, uses the linear method of analysis, which is a standard method described by Hosmer and Lemeshow. In this system the risk applies to an individual and is simpler to use.It is now mandatory for surgeons to audit there clinical work. Simple counting of post operative deaths and complications is not fair and produces misleading comparisons between surgeons, clinical teams and hospitals. An adjustment for case mix is needed and POSSUM scoring has been one method that has been explored over the past decade. Most clinicians are familiar with the data items collected in the physiological and operative data sets, but there seems to be a bewildering array of regression equations and techniques of analysis. In fast, the choice is relatively limited. To monitor general surgical procedures between surgeons and hospitals, the original POSSUM equation using exponential analysis should be used. If the standard linear methodology is used for analysis then P-POSSUM equation must be employed. Vascular surgeons have validated P-POSSUM methodology, although a different regression equation is likely to emerge for each of the index procedures. POSSUM methodology, and in particular the data set, has been used to successfully to compare the performance of general and specialist surgeons between hospitals and across continents. Surgeons who publish comparative data must, however document explicitly the regression equation and method of analysis used to obtain observed: expected outcome results. POSSUM has acknowledged limitations; the equations perform poorly in predicting death in procedures that have very low associated mortality rate. Low risk, high-volume operations are often better audited using process measures rather than outcome. Similarly it predicts only 30-day mortality. The use of POSSUM to predict long term outcome has yet 
Evaluation of Possum Scoring In Patients Undergoing Emergency Laparotomy for Hollow Viscus..

to be validated. Still, of all the scoring systems currently available, there is most experience with POSSUM in both specialist and non specialist surgery. Items in the POSSUM data set are commonly collected and are in many hospital databases. Other systems that require invasive tests \{e.g. blood gases\} must be used with caution if these investigations are not a part of routine care; no procedure is without complication. The results of comparative audit with POSSUM cannot be used to attribute blame. Patient care is the responsibility of individual surgeons, but the outcomes often depend on a large multidisciplinary team comprising surgeons, anesthetists, intensive care staff, junior doctors and nurses, all of whom may affect the complication and death rates. It is unhelpful to look at complications purely in terms of surgical blame anastamotic leaks can be due to poor nutrition \} or anesthetic blame \{myocardial infarction may be precipitated by the stress of a prolonged operation $\}$. Where audit shows a change in mortality rates and a significant increase in observed : expected ratio, the practice of an entire team should be reviewed. POSSUM is simply a tool for fair comparative audit and its methodology currently stands comparison with other sophisticated methods of case- mix analysis, such as APACHE and Bayes.

Data analysis and results

\begin{tabular}{|l|l|l|l|l|l|}
\hline \multicolumn{1}{|l|}{ Diagnosis } & Frequency & Percent & $\begin{array}{l}\text { Valid } \\
\text { Percent }\end{array}$ & $\begin{array}{l}\text { Cumulative } \\
\text { Percent }\end{array}$ \\
\hline \multirow{5}{*}{ Valid } & appendicular perforation & 11 & 11.0 & 11.0 & 11.0 \\
\cline { 2 - 6 } & colon Perforation & 3 & 3.0 & 3.0 & 14.0 \\
\cline { 2 - 6 } & duodenal perforation & 75 & 75.0 & 75.0 & 89.0 \\
\cline { 2 - 6 } & gastric perforation & 3 & 3.0 & 3.0 & 92.0 \\
\cline { 2 - 6 } & gastric perforation with growth & 1 & 1.0 & 1.0 & 93.0 \\
\cline { 2 - 6 } & ileal perforation & 7 & 7.0 & 7.0 & 100.0 \\
\cline { 2 - 6 } & Total & 100 & 100.0 & 100.0 & \\
\hline
\end{tabular}

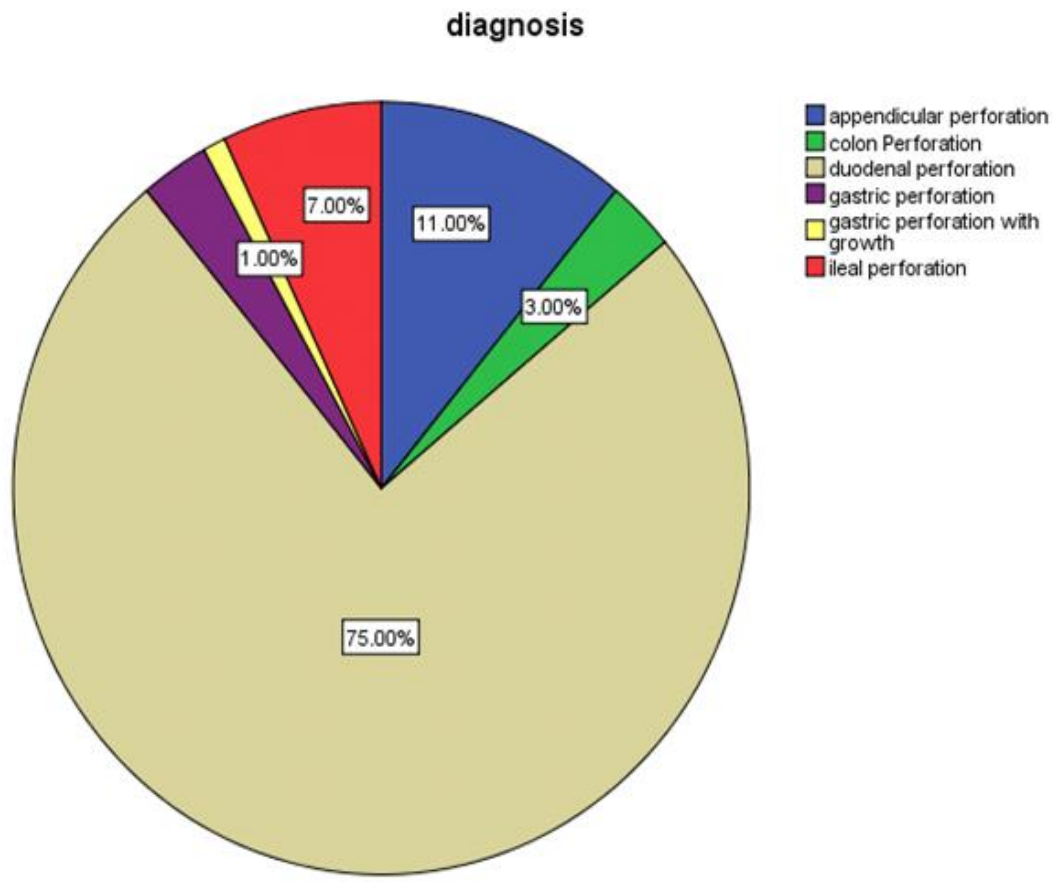

Distribution of diagnosis of the patients in study

\begin{tabular}{|c|c|c|c|c|c|}
\hline \multicolumn{6}{|c|}{ Procedure } \\
\hline & & Frequency & Percent & $\begin{array}{l}\text { Valid } \\
\text { Percent }\end{array}$ & $\begin{array}{l}\text { Cumulative } \\
\text { Percent }\end{array}$ \\
\hline \multirow[t]{9}{*}{ Valid } & appendectomy & 11 & 11.0 & 11.0 & 11.0 \\
\hline & Colostomy & 1 & 1.0 & 1.0 & 12.0 \\
\hline & hemicolectomy & 1 & 1.0 & 1.0 & 13.0 \\
\hline & Ileostomy & 1 & 1.0 & 1.0 & 14.0 \\
\hline & omental patch closure & 75 & 75.0 & 75.0 & 89.0 \\
\hline & primary closure & 7 & 7.0 & 7.0 & 96.0 \\
\hline & primary closure with FJ & 1 & 1.0 & 1.0 & 97.0 \\
\hline & resection and anastamosis & 3 & 3.0 & 3.0 & 100.0 \\
\hline & Total & 100 & 100.0 & 100.0 & \\
\hline
\end{tabular}


Analysis of procedures patient underwent in the study

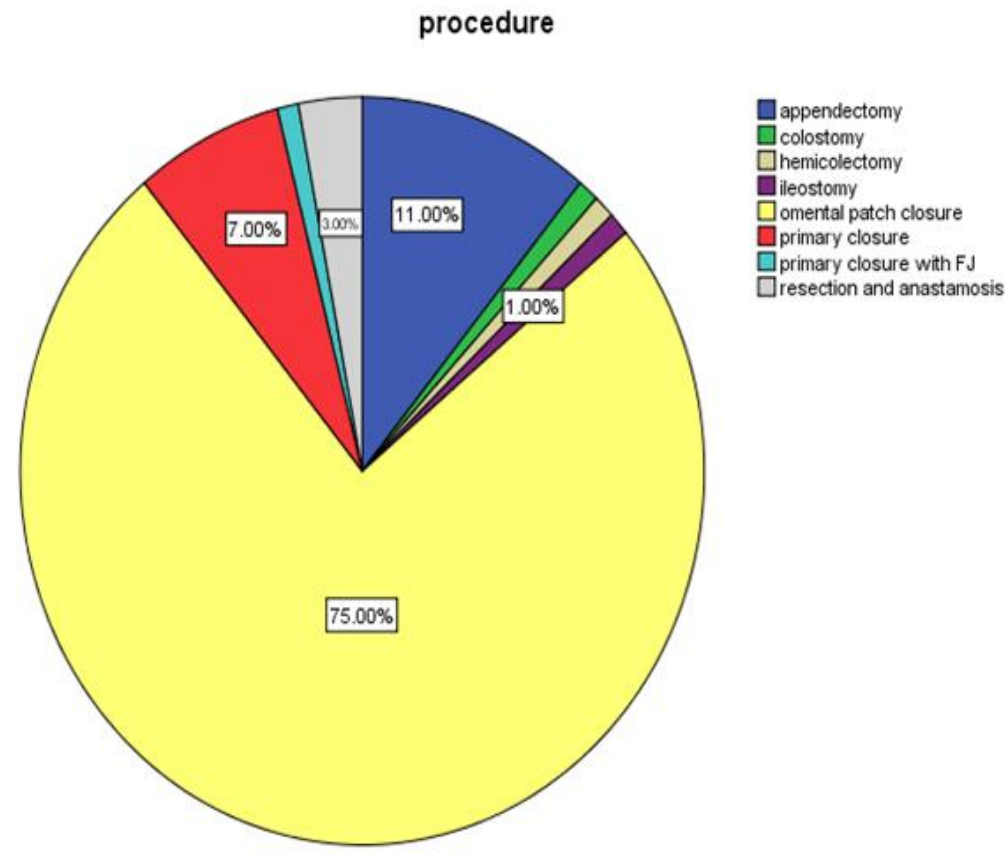

\begin{tabular}{|l|l|l|l|l|l|}
\hline \multicolumn{2}{|l|}{ age range } & Frequency & Percent & Valid Percent & $\begin{array}{l}\text { Cumulative } \\
\text { Percent }\end{array}$ \\
\hline \multirow{4}{*}{ Valid } & 1 to 10 & 1 & 1.0 & 1.0 & 1.0 \\
\cline { 2 - 6 } & 11 to 20 & 5 & 5.0 & 5.0 & 6.0 \\
\cline { 2 - 6 } & $21-30$ & 24 & 24.0 & 24.0 & 30.0 \\
\cline { 2 - 6 } & $31-40$ & 13 & 13.0 & 13.0 & 43.0 \\
\cline { 2 - 6 } & $41-50$ & 28 & 28.0 & 28.0 & 71.0 \\
\cline { 2 - 6 } & $51-60$ & 18 & 18.0 & 18.0 & 89.0 \\
\cline { 2 - 6 } & $61-70$ & 9 & 9.0 & 9.0 & 98.0 \\
\cline { 2 - 6 } & $71-80$ & 2 & 2.0 & 2.0 & 100.0 \\
\cline { 2 - 6 } & Total & 100 & 100.0 & 100.0 & \\
\hline
\end{tabular}

Age distribution of the patients in the study

age range

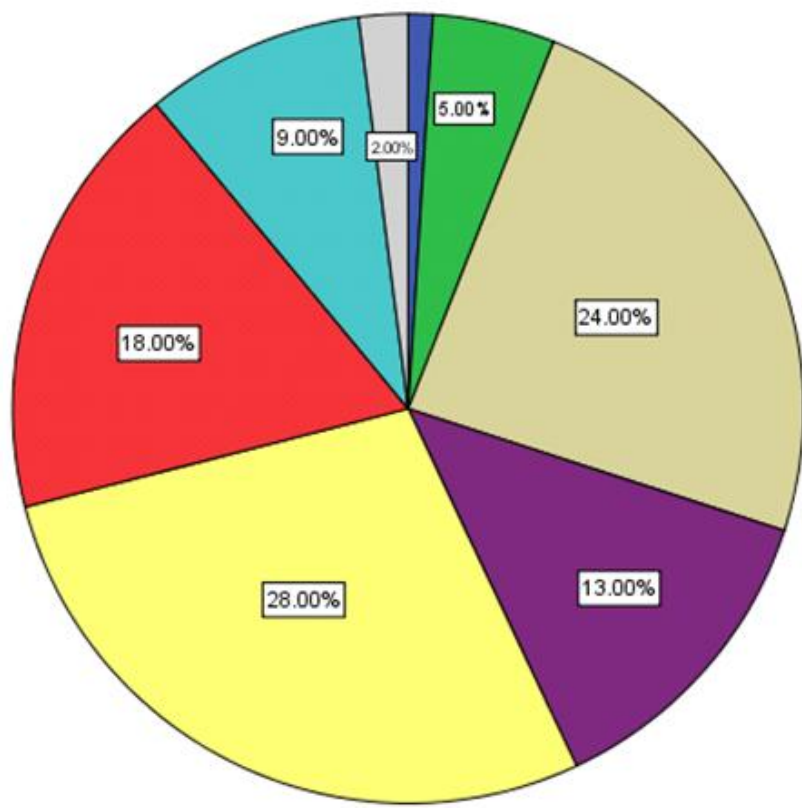

1 to 10

员 11 to 20

21-30

$31-40$

$41-50$

吕1 60

$61-70$

$\square 71-80$ 


\section{Possum predicted morbidity}

Bar Chart

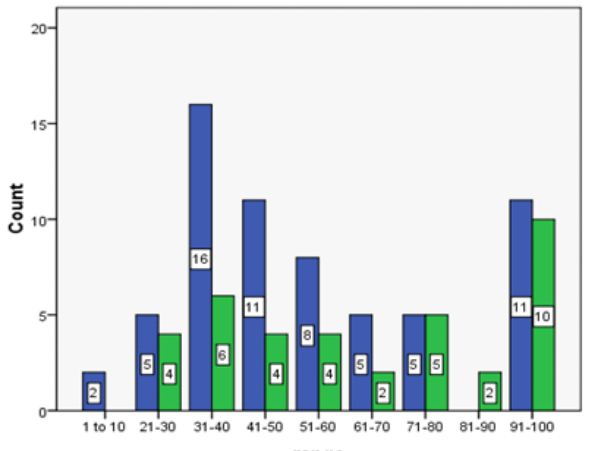

range 量品e

Possum predicted morbidity

\begin{tabular}{|l|l|l|l|l|l|}
\hline & & Frequency & Percent & Valid Percent & Cumulative Percent \\
\hline Valid & 1 to 10 & 2 & 2.0 & 2.0 & 2.0 \\
\cline { 2 - 6 } & $21-30$ & 9 & 9.0 & 9.0 & 11.0 \\
\cline { 2 - 6 } & $31-40$ & 22 & 22.0 & 22.0 & 33.0 \\
\cline { 2 - 6 } & $41-50$ & 15 & 15.0 & 15.0 & 48.0 \\
\cline { 2 - 6 } & $51-60$ & 12 & 12.0 & 12.0 & 60.0 \\
\cline { 2 - 6 } & $61-70$ & 7 & 7.0 & 7.0 & 67.0 \\
\cline { 2 - 6 } & $71-80$ & 10 & 10.0 & 10.0 & 77.0 \\
\cline { 2 - 6 } & $81-90$ & 2 & 2.0 & 2.0 & 79.0 \\
\cline { 2 - 6 } & $91-100$ & 21 & 21.0 & 21.0 & \\
\cline { 2 - 5 } & Total & 100 & 100.0 & 100.0 & \\
\hline
\end{tabular}

observed morbidity

\begin{tabular}{|c|c|c|c|c|c|}
\hline & & Frequency & Percent & Valid Percent & $\begin{array}{l}\text { Cumulative } \\
\text { Percent }\end{array}$ \\
\hline \multirow[t]{9}{*}{ Valid } & & 63 & 63.0 & 63.0 & 63.0 \\
\hline & anastamotic leak & 1 & 1.0 & 1.0 & 64.0 \\
\hline & ARDS & 1 & 1.0 & 1.0 & 65.0 \\
\hline & hypokalemia & 2 & 2.0 & 2.0 & 67.0 \\
\hline & pnemonia & 3 & 3.0 & 3.0 & 70.0 \\
\hline & UTI & 3 & 3.0 & 3.0 & 73.0 \\
\hline & wound infection & 12 & 12.0 & 12.0 & 85.0 \\
\hline & wound dehiscence & 15 & 15.0 & 15.0 & 100.0 \\
\hline & Total & 100 & 100.0 & 100.0 & \\
\hline
\end{tabular}

Tables of expected and observed morbidity of patients

Possum predicted mortality

\begin{tabular}{|c|c|c|c|c|c|}
\hline & & Frequency & Percent & Valid Percent & $\begin{array}{c}\text { Cumulative } \\
\text { Percent }\end{array}$ \\
\hline \multirow[t]{10}{*}{ Valid } & 1 to 10 & 46 & 46.0 & 46.0 & 46.0 \\
\hline & 11 to 20 & 26 & 26.0 & 26.0 & 72.0 \\
\hline & $21-30$ & 5 & 5.0 & 5.0 & 77.0 \\
\hline & $31-40$ & 2 & 2.0 & 2.0 & 79.0 \\
\hline & $41-50$ & 3 & 3.0 & 3.0 & 82.0 \\
\hline & $51-60$ & 8 & 8.0 & 8.0 & 90.0 \\
\hline & $61-70$ & 2 & 2.0 & 2.0 & 92.0 \\
\hline & $81-90$ & 3 & 3.0 & 3.0 & 95.0 \\
\hline & $91-100$ & 5 & 5.0 & 5.0 & 100.0 \\
\hline & Total & 100 & 100.0 & 100.0 & \\
\hline
\end{tabular}

Tables of expected and observed mortality of patients

observed mortality

\begin{tabular}{|l|l|r|r|r|r|}
\hline & & \multicolumn{1}{|c|}{ Frequency } & \multicolumn{1}{c|}{ Percent } & Valid Percent & \multicolumn{1}{c|}{$\begin{array}{c}\text { Cumulative } \\
\text { Percent }\end{array}$} \\
\hline \multirow{3}{*}{ Valid } & discharged & 96 & 96.0 & 96.0 & 96.0 \\
\cline { 2 - 6 } & EXPIRED & 4 & 4.0 & 4.0 & 100.0 \\
\cline { 2 - 6 } & Total & 100 & 100.0 & 100.0 & \\
\hline
\end{tabular}


range * observed mortality Crosstabulation

\begin{tabular}{|c|c|c|c|c|}
\hline \multicolumn{5}{|c|}{ Count } \\
\hline & & \multicolumn{2}{|c|}{ observed mortality } & \multirow[t]{2}{*}{ Total } \\
\hline & & discharged & EXPIRED & \\
\hline \multirow[t]{9}{*}{ range } & 1 to 10 & 46 & 0 & 46 \\
\hline & 11 to 20 & 26 & 0 & 26 \\
\hline & $21-30$ & 5 & 0 & 5 \\
\hline & $31-40$ & 2 & 0 & 2 \\
\hline & $41-50$ & 3 & 0 & 3 \\
\hline & $51-60$ & 8 & 0 & 8 \\
\hline & $61-70$ & 2 & 0 & 2 \\
\hline & $81-90$ & 2 & 1 & 3 \\
\hline & $91-100$ & 2 & 3 & 5 \\
\hline \multicolumn{2}{|l|}{ Total } & 96 & 4 & 100 \\
\hline
\end{tabular}

range * observed morbidity Crosstabulation

\begin{tabular}{|c|c|c|c|c|c|c|c|c|c|c|}
\hline \multicolumn{11}{|c|}{ Count } \\
\hline & & \multicolumn{8}{|c|}{ observed morbidity } & \multirow[t]{2}{*}{ Total } \\
\hline & & & $\begin{array}{c}\text { anastamotic } \\
\text { leak }\end{array}$ & ARDS & hypokalemia & pnemonia & UTI & $\begin{array}{l}\text { wound } \\
\text { infection }\end{array}$ & $\begin{array}{c}\text { wound } \\
\text { dehiscence }\end{array}$ & \\
\hline \multirow[t]{9}{*}{ range } & 1 to 10 & 2 & 0 & 0 & 0 & 0 & 0 & 0 & 0 & 2 \\
\hline & $21-30$ & 5 & 0 & 0 & 0 & 0 & 0 & 2 & 2 & 9 \\
\hline & $31-40$ & 16 & 0 & 1 & 0 & 0 & 0 & 4 & 1 & 22 \\
\hline & $41-50$ & 11 & 0 & 0 & 0 & 1 & 2 & 0 & 1 & 15 \\
\hline & $51-60$ & 8 & 0 & 0 & 1 & 0 & 0 & 2 & 1 & 12 \\
\hline & $61-70$ & 5 & 0 & 0 & 0 & 0 & 0 & 1 & 1 & 7 \\
\hline & $71-80$ & 5 & 1 & 0 & 0 & 1 & 0 & 0 & 3 & 10 \\
\hline & $81-90$ & 0 & 0 & 0 & 0 & 0 & 0 & 0 & 2 & 2 \\
\hline & $91-100$ & 11 & 0 & 0 & 1 & 1 & 1 & 3 & 4 & 21 \\
\hline \multicolumn{2}{|c|}{ Total } & 63 & 1 & 1 & 2 & 3 & 3 & 12 & 15 & 100 \\
\hline
\end{tabular}

Mortality significance

\begin{tabular}{|c|c|c|c|}
\hline \multicolumn{4}{|l|}{ Chi-Square Tests } \\
\hline & Value & $\mathrm{df}$ & $\begin{array}{l}\text { Asymp. Sig. } \\
\text { sided) }\end{array}$ \\
\hline Pearson Chi-Square & $51.389^{\mathrm{a}}$ & 8 & .000 \\
\hline Likelihood Ratio & 23.040 & 8 & .003 \\
\hline $\mathrm{N}$ of Valid Cases & 100 & & \\
\hline
\end{tabular}

a. 15 cells $(83.3 \%)$ have expected count less than 5 . The minimum expected count is .08 .

\section{Bibliography}

[1]. Sagar PM, Hartley MN, Mancey-Jones B, Sedman PC, May J, Macfie J

[2]. Comparative audit of colorectal resection with the POSSUM scoring system. Br J Surg 1994; 81:1492-1494.

[3]. Copeland GP, Jones D, Wilcox A, Harris PL. Comparative vascular audit using POSSUM scoring system. Ann R CollSurgEngl 1993; 75 : 175-177

[4]. Copeland GP, Sagar P, Brennan J, Roberts G, Ward J, Cornford P et al. Riskadjusted analysis of surgeon performance: a 1-year study. Br J Surg 1995; 82:408-411.

[5]. Murray GD, Hayes C, Fowler S, Dunn DC, Presentation of comparative audit data. Br J Surg 1995; 82: $329-332$.

[6]. Lyons C, Gumpert R. Medical audit data: counting is not enough. BMJ 1990; 300: 1563-1566.

[7]. Jones HJS, de Cossart L. Risk scoring in surgical patients. Br J Surg 1998;86: 147-159.

[8]. Copeland GP. Comparative audit: fact versus fantasy. Br J Surg 1993; 80:1424-1425.

[9]. Copeland GP. Surgical scoring risk assessment and the surgeon. J R Coll SurgEdinb 1992; 37: 145-148.

[10]. Copeland GP,Jones D, Walters M. POSSUM: a scoring system for surgical audit. Br J Surg 1991; 78: 355-360.

[11]. Jones DR, Copeland GP, de Cossart L. Comparison of POSSUM with APACHE II for prediction of outcome from high-dependency unit. Br J Surg 1992; 79: 1293-1296.

[12]. Whiteley MS, Prytherch DR, Higgins B, Weaver PC, Prout WG. An evaluation of the POSSUM surgical scoring system. Br J Surg 1996; 83: 812-815.Prytherch DR, Whiteley MS, Higgins B, Weaver PC, Prout WG, Powell SJ.

[13]. POSSUM and Portsmouth POSSUM for predicting mortality. Physiological and Operative Severity score for the enUmeration of Mortality and Morbidity. Br J Surg 1998; 85: 1217-1220.

[14]. Wijesinghe LD, Mahmood T, Scott DJA, Berridge DC, Kent PJ, Kester RC. Comparison of POSSUM and the Portsmouth predictor equation for predicting death following vascular surgery. Br J Surg 1998; 83: 209-212.

[15]. Tekkis PP, Kocher HM, Bentley AJ, Cullen PT, South LM, Trotter GA et al. Operative mortality amongst surgeons: comparison of POSSUM and PPOSSUMscoring systems in gastrointestinal surgery. Dis Colon Rectum 2000; 43: 1528-1532.

[16]. Wang TK, Tu HH. Colorectal perforation with barium enema in elderly: case analysis with the POSSUM scoring system. J Gasteroenterol 1998; 33: 201-205.

[17]. Sagar PM, Hartley MN, Macfie J, Taylor BA, Copeland GP. Comprison of individual surgeon's performance. Risk-adjusted analysis with POSSUM scoring system. Dis Colon Rectum 1996; 39: 654-658.

[18]. Brunelli A, Fianchini A, Xiume P, Gesuita R, Mattei A, Carle F. Evaluation of POSSUM scoring system in lung surgery. Physiological and Operative Severity score for the enUmeration of Mortality and Morbidity. Thoracic CardiovascSurg 1998; 46: $141-146$

[19]. Copeland GP. The POSSUM system of surgical audit. Arch Surg 2002; 137:15-19. 
Evaluation of Possum Scoring In Patients Undergoing Emergency Laparotomy for Hollow Viscus..

[20]. Neary WD, Heather BP, Earnshaw JJ. Physiological and Operative Severity score for the enUmeration of Mortality and Morbidity (POSSUM). Br J Surg 2003; 90: 157-165.R.S. Mohil, D. Bhatnagar, L. Bahadur, Rajneesh, D.K. Dev, M. Magan.

[21]. POSSUM and P-POSSUM for risk-adjusted audit of patients undergoing emergency laparotomy. Br J Surg 2004; 91: 500-503.

[22]. Hosmer D, Lemeshow S, A goodness of fit test for multiple logistic regression models. Community Statistics 1980; 10: 1043-1069.

[23]. Gotohda N, Iwagaki H, Itano S, Horiki S, Fujiwara T, Saito S et al. can POSSUM, a scoring system for perioperative surgical risk, predictpostoperative clinical course? Acta Med Okayama 1998; 52: 325-329.

[24]. Yii MK, Nj KJ. Risk-adjusted scoring audit with POSSUM scoring system ina developing country. Physiological and Operative Severity score for the enumeration of Mortality and Morbidity. Br J Surg 2002; 89: 110-113.

[25]. Copeland GP. Assessing the surgeon: 10 years' experience with the POSSUMsystem. J Clin Excellence 2000; 2: 187-190.

\section{Physiological data set and scores for POSSUM}

\begin{tabular}{|c|c|c|c|c|}
\hline & 1 & 2 & 4 & 8 \\
\hline AGE(in years) & $<60$ & 61-70 & $>71$ & \\
\hline $\begin{array}{l}\text { Cardiac signs } \\
\text { Chest radiography }\end{array}$ & No failure & $\begin{array}{l}\text { Diuretic,Digoxin } \\
\text { Anti-Angina/Hypertensive } \\
\text { Therapy }\end{array}$ & $\begin{array}{l}\text { Peripheral } \\
\text { Edema, } \\
\text { Warfarin Therapy, } \\
\text { Boderline } \\
\text { Cardiomegaly }\end{array}$ & $\begin{array}{l}\text { Raised JVP, } \\
\text { Cardiomegaly }\end{array}$ \\
\hline $\begin{array}{l}\text { Respiratory } \\
\text { History,Chest } \\
\text { Radiography }\end{array}$ & $\begin{array}{l}\text { No } \\
\text { dyspnoea }\end{array}$ & $\begin{array}{l}\text { Dyspnoea on exertion } \\
\text { Mild CAOD }\end{array}$ & $\begin{array}{l}\text { Limiting } \\
\text { dyspnoea(one on } \\
\text { flight) } \\
\text { Moderate COAD } \\
\end{array}$ & $\begin{array}{l}\text { Dyspnoea at } \\
\text { rest(rate }>30 / \text { min) } \\
\text { Fibrosis/ } \\
\text { Consolidation } \\
\end{array}$ \\
\hline Blood pressure(systolic)(mmhg) & 110-130 & $\begin{array}{l}131-170 \\
100-109 \\
\end{array}$ & $\begin{array}{l}>171 \\
90-99\end{array}$ & $\begin{array}{l}- \\
<89\end{array}$ \\
\hline Pulse(beats/min) & $50-80$ & 81-100 & 101-120 & $>121$ \\
\hline Glasgow coma scale & 15 & $12-14$ & 9-11 & $<8$ \\
\hline $\begin{array}{l}\text { Hemoglobin } \\
\text { (g/dl) }\end{array}$ & 13-16 & $\begin{array}{l}11.5-12.9 \\
16.1-17.0 \\
\end{array}$ & $\begin{array}{l}10.0-11.4 \\
17.1-18.0 \\
\end{array}$ & $\begin{array}{l}<9.9 \\
>18.1\end{array}$ \\
\hline $\begin{array}{l}\text { White cell count } \\
\left(\mathbf{x 1 0}^{\wedge} 9 / /\right)\end{array}$ & 4-10 & $\begin{array}{l}10.1-20.0 \\
3.10-4.0 \\
\end{array}$ & $\begin{array}{l}>20.1 \\
<3.0\end{array}$ & - \\
\hline Urea(mEq/l) & $<7.4$ & 7.6-10 & 10.1-15.0 & $>15.1$ \\
\hline $\begin{array}{l}\text { Sodium } \\
(\mathrm{mEq} / \mathrm{l})\end{array}$ & $>136$ & 131-135 & $126-130$ & $<126$ \\
\hline $\begin{array}{l}\text { Potassium } \\
(\mathrm{mEq} / \mathrm{l})\end{array}$ & 3.5-5.0 & \begin{tabular}{|l|}
$3.2-3.4$ \\
$5.1-5.3$ \\
\end{tabular} & $\begin{array}{l}2.9-3.1 \\
5.4-5.9 \\
\end{array}$ & $\begin{array}{l}<2.8 \\
>6.0\end{array}$ \\
\hline Electrocardiogram & Normal & - & $\begin{array}{l}\text { Atrial Fibrillation } \\
(60-90)\end{array}$ & $\begin{array}{l}\text { Any other } \\
\text { abnormal rhythm } \\
\text { or }>5 \text { ectopics/min } \\
Q \quad \text { waves } / \mathrm{ST} / \mathrm{T} \\
\text { wave changes }\end{array}$ \\
\hline
\end{tabular}

Operative severity data set and scores for POSSUM

\begin{tabular}{|l|l|l|l|l|}
\hline & 1 & 2 & 4 & 8 \\
\hline $\begin{array}{l}\text { Operative } \\
\text { Severity }\end{array}$ & Minor & Moderate & Major & Major+ \\
\hline Multiple procedures & 1 & - & 2 & $>2$ \\
\hline Total Blood loss(ml) & $<100$ & $\mathbf{1 0 1 - 5 0 0}$ & $\mathbf{5 0 1 - 9 9 9}$ & $>1000$ \\
\hline $\begin{array}{l}\text { Peritoneal } \\
\text { Soiling }\end{array}$ & None & $\begin{array}{l}\text { Minor(serous } \\
\text { Fluid) }\end{array}$ & Local Pus & $\begin{array}{l}\text { Free } \\
\text { content,Pus or blood }\end{array}$ \\
\hline $\begin{array}{l}\text { Presence } \\
\text { malignancy }\end{array}$ & None & $\begin{array}{l}\text { Primary } \\
\text { only }\end{array}$ & Nodal metastasis & Distant metastasis \\
\hline $\begin{array}{l}\text { Mode of surgery } \\
\text { Elective }\end{array}$ & - & $\begin{array}{l}\text { Emergency } \\
\text { Resuscitation } \\
\text { Of }>2 \mathrm{~h}, \text { possible }<24 h \\
\text { after admission }\end{array}$ & $\begin{array}{l}\text { Emergency } \\
\text { immediate) } \\
\text { Surgery }<2 \mathrm{~h} \text { needed }\end{array}$ \\
\hline
\end{tabular}

